\title{
Preparation and Characterization of Bis-Propargyl-Succinate, and its Application in Preliminary Healing Ability of Crosslinked Polyurethane using "Azide-Alkyne” Click
}

\author{
Thi Sinh Vo ${ }^{* *}$ and Tran Thi Bich Chau Vo ${ }^{2}$ \\ ${ }^{1}$ School of Mechanical Engineering, Sungkyunkwan University, Suwon 16419, Republic of Korea. \\ ${ }^{2}$ Department of Industrial Management, Can Tho University, Can Tho, Vietnam.
}

Received 15 June 2020; Accepted 25 July 2020

\begin{abstract}
With the development of current technology, many concepts of self-healing materials have recently been proposed. In this study, a preliminary healing ability is investigated by injecting a well-fabricated healing agent (bis-propargylsuccinate, BPS) into a crosslinked polymer (glycidyl azide polymer-based polyurethane, GAP-based PU) with the different assuming cuts. The results suggest that the stress at break of BPS injected the cut regions of the crosslinked $\mathrm{PU}$ is in the range of $0.169-0.218 \mathrm{MPa}$ comparing with $0.244 \mathrm{MPa}$ of the cut regions of the crosslinked PU, and the highest preliminary healing efficiency of BPS injected the cut regions of the crosslinked PU is achieved to be $86.0 \%$. Moreover, the preliminary healing mechanism can base on the diffusion of BPS into the cut regions of the crosslinked $\mathrm{PU}$, as well as the healed regions of the crosslinked PU with the different assuming cuts are stronger owing to the preliminary healable "azide-alkyne" click. As such, BPS is employed as a healing agent, as well as it becomes a promising candidate to apply for self-healing materials in crosslinked PU. Therefore, the synthesized BPS is injected to repair the damaged regions of the crosslinked PU in our first study, it is considered as new method to develop more study for capsule-based self-healing materials.
\end{abstract}

Keywords: Glycidyl azide polymer (GAP), Polyurethane, Preliminary healing ability, Azide-alkyne click.

\section{Introduction}

With the development of the technology, lots of concepts of self-healing materials have recently been proposed. Moreover, the self-healing material is one of trending topics, which is concerned as an artificial or synthetically-created material to be automatically repaired damages to themselves without any external diagnosis or human intervention. Basing on selfhealing mechanisms, the self-healing materials can be classified primarily into three approaches, such as capsule based, vascular and intrinsic. In addition, the cracks and damages are regularly appeared in the polymeric materials due to the effect of environment in the employed long-term, which not only impacts to the mechanical properties but also losses of the function of these polymeric materials [1-4]. Besides, the traditional techniques are considered to be a significant role in maintaining materials properties with further resources and energy. In order to overcome this challenge, the material with self-repairing ability in the damaged polymer matrix is considered as a healing agent, which is truly attracted to investigate for reliable and durable abilities [2-5]. Therefore, it is relatively important to design and synthesize successfully the healing agent to be applied for the self-healing materials.

A reaction of an azide and a terminal alkyne compounds [6-8] is named Huisgen 1,3-dipolar cycloaddition reaction or "azide-alkyne" click, which is considered as an excellent candidate for the synthesis of advanced polymeric materials with many attributes of the Huisgen reaction to obtain needed

*E-mail address: vtsinh92@skku.edu

ISSN: 1791-2377 @ 2020 School of Science, IHU. All rights reserved.

doi:10.25103/jestr.134.10 advantageous [9-13]. Actually, it is easy to introduce azides and acetylenes into organic compounds, and these structures are stable under other reaction conditions [7, 14]. These characteristics have made the Huisgen reaction a powerful linking reaction in drug discovery, polymer synthesis, and nanoparticle and bio-macromolecule functionalization $[6,15$, 16]. To expand the self-healing materials using "azide-alkyne" click in the first study, in our study, bis-propargyl-succinate (BPS) as an alkyne compound has been chosen as a healing agent, it can be synthesized easily by one-stage method from cheap reactants (Figure 1a). For the azido compound glycidyl azide polymer (GAP) as an azide compound is chosen because of its commercial availability. Chemical structure of GAP contains two functional groups [i.e.: azide and hydroxyl (diol)]. Basing on available hydroxyl (diol, $-\mathrm{OH}$ ) groups on GAP chain, it is conducted to react with isocyanate $(-\mathrm{N}=\mathrm{C}=\mathrm{O})$ compound to form crosslinked polyurethane (GAP-based polyurethane, GAP-based PU) (Figure 1b). In addition to this reaction, the available azide groups on GAP chain can react with alkyne compound to form crosslinked GAP as well. Especially, before the use of the self-healing materials from GAP-based PU, the preliminary healing ability on the selfhealing materials is significant important to investigate whole in the first study. Therefore, the synthesized BPS is injected to repair the damaged regions of the crosslinked PU in our first study, it is considered as new method to develop more the self-heling materials.

Herein, BPS with terminal alkyne group is designed and synthesized to be injected into crosslinked polyurethane (GAP-based PU) via "azide-alkyne" click (Figure 1c). This is seen as a new method to survey healing ability in the first studies of this material. Besides, in order to become a precondition on this self-healing material basing on GAP- 
based PU, a preliminary healing ability consisting of a healing agent (BPS) and a crosslinked polymer (GAP-based PU) with the different assuming cuts (i.e.: seven specimens of crosslinked PUs with the different assuming cuts are designed as shown in Figure 2) is explored through injection method. Moreover, their preliminary healing behavior is investigated through visual observation and mechanical property, as well as the preliminary healing mechanism at the healed positions of the specimens is clearly explained. The main goal of this research is to be based on the preliminary healing ability of this crosslinked PU using "azide-alkyne" click to further probably study for capsule-based self-healing materials in the future works.

\section{Materials and Methods}

\subsection{Materials}

Magnesium sulfate anhydrous $\left(\mathrm{MgSO}_{4}\right)$ (99.5\%) were purchased from Junsei Chemical Co. Ltd (Japan). Glycidyl azide polymer (GAP) polyols (Table 1) was offered from Korean Company. Propargyl alcohol (PPA) 99.0\% was provided from Sigma-Aldrich Company. Succinic anhydride (SA) 99.0\%, N-N'-dicyclohexylcarnodiimide (DCC) 99.0\% and 4-(Dimethylamino)pyridine (DMAP) $99.0 \%$ were obtained from Alfa Aesar Company. Dichloromethane (MC) 99.5\% were purchased from Samchun Company. Chloroform- $d_{1}\left(\mathrm{CDCl}_{3}\right)(0.03 \%$ vol, TMS $)$ was received from Merck KGaA (Germany).

Table 1. Properties of GAP polyol.

\begin{tabular}{|c|c|}
\hline Property & Result \\
\hline $\begin{array}{l}\text { Appearance } \\
\text { Viscosity } \\
\text { Density } \\
\text { Hydroxyl equivalent } \\
\text { weight } \\
\text { Water content } \\
\text { Functionality }\end{array}$ & $\begin{array}{l}\text { Amber liquid } \\
12 \mathrm{~Pa} . \mathrm{s} \\
1.3 \mathrm{~g} / \mathrm{mL} \\
2,000 \\
0.02 \% \\
\text { Between } 2.5 \text { to } 3 \\
\text { hydroxyl groups per } \\
\text { molecule. } \\
\text { Gum stocks with } 1: 1 \\
\mathrm{NCO} / \mathrm{OH} \text { typically } \\
\text { require added catalyst at } \\
58{ }^{\circ} \mathrm{C} \text { in a reasonable } \\
\text { time. }\end{array}$ \\
\hline
\end{tabular}

\subsection{Synthesis of bis-propargyl-succinate}

A mixture of SA $(0.0250 \mathrm{~mol})$, PPA $(0.0520 \mathrm{~mol})$, DMAP $(3.327 \mathrm{mmol}), \mathrm{DCC}(0.0250 \mathrm{~mol})$ and $\mathrm{MC}$ solvent are stirred in a two-necked round bottom flask at room temperature. After 24 hours, the solution is filtered by filter paper, and which is washed with water for three times. The orginic extracts are dried over $\mathrm{MgSO}_{4}$ and the solvent is removed by Rotary evaporators. The final crude product is purified by column chromatography (silica gel, ethylacetate/hexane (v/v) $=5 / 5)$. The reaction scheme of bis-propargyl-succinate (BPS) is shown in Figure 1a.

BPS $\left(\mathrm{C}_{10} \mathrm{H}_{10} \mathrm{O}_{4}, \mathrm{MW}=194.187 \mathrm{~g} / \mathrm{mol}\right):{ }^{1} \mathrm{H}$ NMR $(300 \mathrm{MHz}$, $\left.\mathrm{CDCl}_{3}, \mathrm{ppm}\right) \delta=4.64$ (d, $\left.4 \mathrm{H},-\underline{\mathrm{CH}}_{2}-\mathrm{O}-\right) ; 2.64$ (s, 4H, - $\underline{\mathrm{H}}_{2}-$ $\mathrm{CO}-) ; 2.47(\mathrm{t}, 2 \mathrm{H}, \underline{\mathbf{H C}} \equiv \mathrm{C}-) .{ }^{13} \mathrm{C} \mathrm{NMR}\left(75 \mathrm{MHz}, \mathrm{CDCl}_{3},{ }_{\mathrm{ppm}}\right)$ $\delta=171.51\left(-\mathrm{OO} \underline{\mathbf{C}}-\mathrm{CH}_{2}-\right) ; 76.97\left(\mathrm{HC} \equiv \underline{\mathbf{C}}-\mathrm{CH}_{2}-\right) ; 75.33$
$(\mathrm{H} \underline{\mathbf{C}} \equiv \mathrm{C}-) ; 52.48\left(\mathrm{HC} \equiv \mathrm{C}-\underline{\mathbf{C}} \mathrm{H}_{2}-\mathrm{O}-\right) ; 28.85\left(-\mathrm{OOC}-\underline{\mathbf{C H}}_{2} \underline{\mathbf{C}} \mathrm{H}_{2}-\right.$ COO-).

\subsection{Preparation of crosslinked polyurethane}

GAP polyol $(8.000 \mathrm{~g}, 80.808 \mathrm{mmol})$ is dried at $60{ }^{\circ} \mathrm{C}$ under vacuum. After $1 \mathrm{~h}$, IPDI $(0.450 \mathrm{~g}, 2.270 \mathrm{mmol})$ is rapidly added into the GAP polyol, which is stirred for $0.5 \mathrm{~h}$ at room temperature. It is similar for $0.150 \mathrm{~g}$ TPB solution $(20 \mathrm{wt} \%$ in benzene solution) and $0.240 \mathrm{~g}$ of DNS solution (12.5 $\mathrm{wt} \%$ in benzene solution). Next, the mixture is pulled into mold $(3 \mathrm{~cm}$ $\mathrm{x} 8 \mathrm{~cm}$ ), which is put in an oven at $30^{\circ} \mathrm{C}$ to remove the bubble under vacuum for $3 \mathrm{~h}$. The curing process is performed in the oven at $60{ }^{\circ} \mathrm{C}$ for 7 days to obtain GAP-based PU. The formation scheme of crosslinked PU (GAP-based PU) is shown in $\quad$ Figure $1 b$. a).

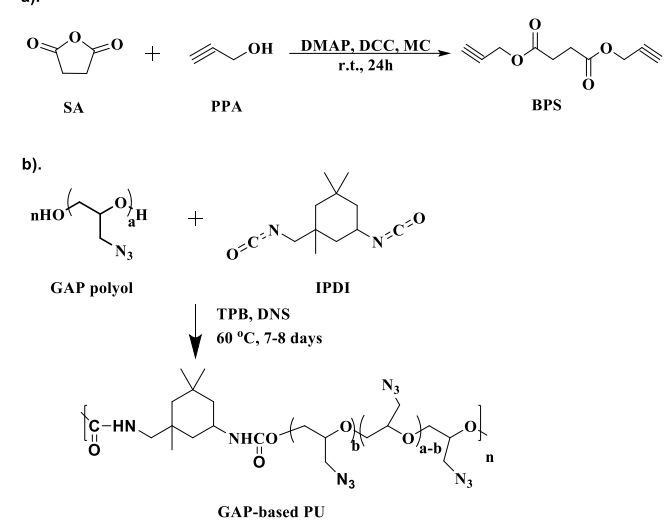

c).

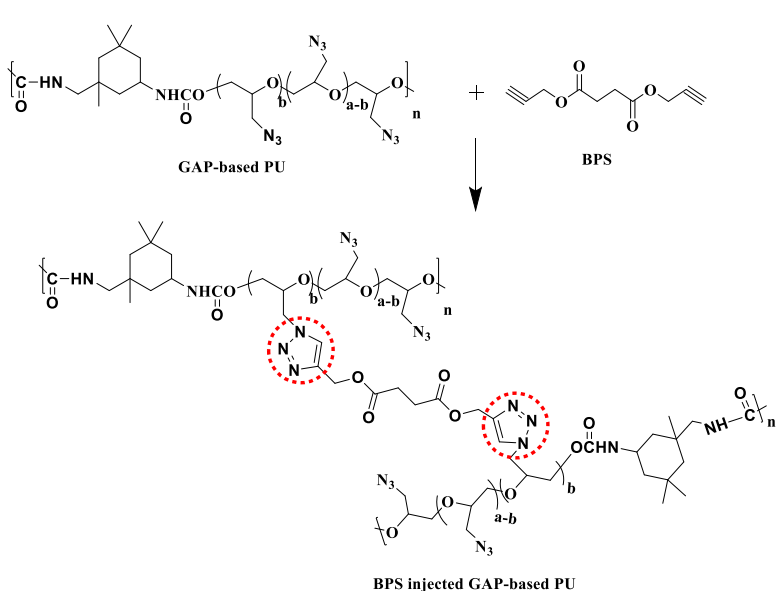

Fig. 1 (a) Synthetic route to the BPS, (b) Formation of the crosslinked PU, (c) "Azide-alkyne" click of the crosslinked PU and BPS.

\subsection{Preparation of bis-propargyl-succinate injected crosslinked polyurethane}

GAP-based PU is cut according to each specimens [(1) - (7)] as shown in Figure 2. The synthesized BPS is injected into the cut surfaces of crosslinked PU, which are connected each other and put in the oven at $60{ }^{\circ} \mathrm{C}$ for 7 days. Next, the bending and stretching forces are employed on these samples to observe the preliminary healing ability of all specimens. Furthermore, these specimens are conducted by measuring the tensile strength test to evaluate their preliminary healing efficiency. The different cutting cases of all specimens (BPS injected crosslinked PU) to apply for tensile strength test are shown in Figure 2, and the "azide-alkyne" click of the cut crosslinked PU and BPS is shown in Figure 1c. 


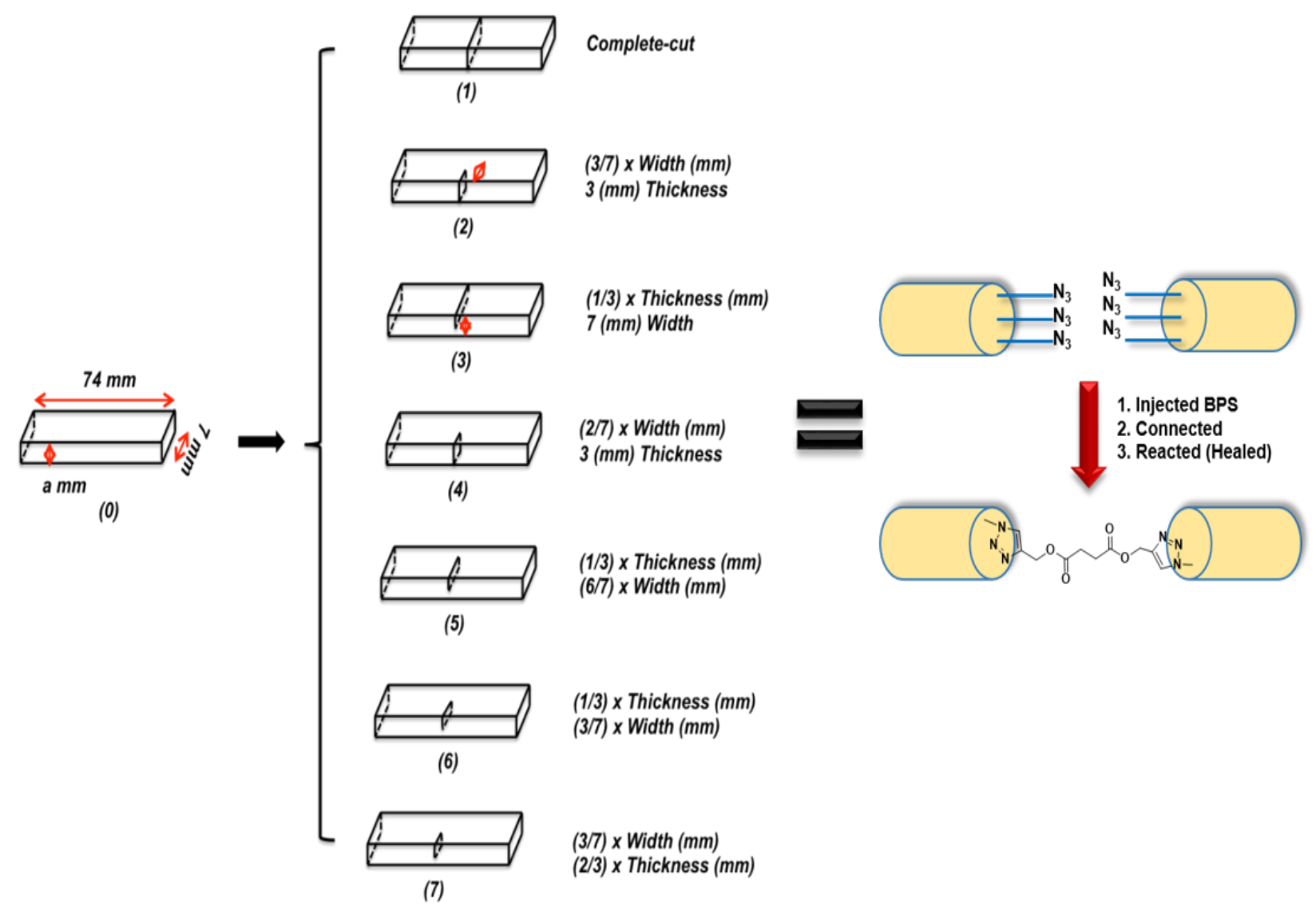

Fig. 2 Different cutting cases of BPS injected crosslinked PU samples for tensile strength test, (0) Origin, (1) Complete-Cutting, (2) Width-Cutting, (3) Thickness-Cutting, (4) - (7) Width \& Thickness-Cuttings.

\subsection{Analysis instruments}

Structure of BPS is confirmed by NMR spectrometer (300 $\mathrm{MHz}$, Varian Mercury Co.). Chemical shifts ( $\delta$ values) are given in parts per million with tetramethylsilane (TMS) as an internal standard. Pure BPS are dissolved in $\mathrm{CDCl}_{3}$ in NMR tubes for measurement. Fourier-transform infrared spectroscopy (FT-IR) is recorded by the spectrophotometer (Nicolet 380, Ietled Co.). The spectrum is scanned in the $4,000-600 \mathrm{~cm}^{-1}$ region. Glass transition temperature is evaluated by differential scanning calorimeter (DSC, DSC8000, PerkinElmer). Glass transition temperature of samples is obtained after cooling to $-120^{\circ} \mathrm{C}$ and subsequently heating to $50{ }^{\circ} \mathrm{C}$ at a heating rate of $10^{\circ} \mathrm{C} / \mathrm{min}$ under the dry nitrogen atmosphere $(20 \mathrm{~mL} / \mathrm{min})$. The decomposition temperature and weight loss of the material are also confirmed by thermogravimetric analysis (TGA, TGA4000, PerkinElmer). Decomposition temperature is conducted from $50{ }^{\circ} \mathrm{C}$ and subsequently heated to $850{ }^{\circ} \mathrm{C}$ at a heating rate of $20^{\circ} \mathrm{C} / \mathrm{min}$ under the dry nitrogen atmosphere $(20 \mathrm{~mL} / \mathrm{min})$. The tensile strength, ultimate elongation and modulus are measured on a universal test machine (TO-100-IC, Test One) with a $20 \mathrm{~kg}$ load cell and software (TestOne_Utm Version 12.0.2) at room temperature. The rate of tensile was $0.8 \mathrm{~mm} / \mathrm{s}$. The tensile test of the samples is cut to $(74 \times 7) \mathrm{mm}^{2}$ (Figure 2). All reported results for the tensile strength; ultimate elongation and initial modulus are the averages of 3 measured values.

\section{Results and Discussion}

\subsection{Characterization of bis-propargyl-succinate}

As known, a general esterification is usually occurred when a carboxylic acid reacts with an alcohol. Besides, the presence of an acid catalyst and heat are one of necessary conditions to can occur this reaction. Actually, it takes a lot of energy to remove - $\mathrm{OH}$ from the carboxylic acid; therefore, a catalyst and heat are relatively necessary to produce the necessary energy. When -OH on the carboxylic acid has been removed, the hydrogen on the alcohol can be removed and that oxygen can be connected to the carbon. Because the oxygen was already connected to a carbon, it is now connected to a carbon on both sides, and an ester is formed. Here, instead of the direct-use of carboxylic acid [17], SA $\left[\left(\mathrm{CH}_{2} \mathrm{CO}\right)_{2} \mathrm{O}\right]$ is an anhydride compound, which is employed to react with an alcohol (PPA, $\left.\mathrm{C}_{3} \mathrm{H}_{3} \mathrm{OH}\right)$. Specially, SA hydrolyzes readily to give succinic acid [e.g.: $\left(\mathrm{CH}_{2} \mathrm{CO}\right)_{2} \mathrm{O}+\mathrm{H}_{2} \mathrm{O} \rightarrow\left(\mathrm{CH}_{2} \mathrm{CO}_{2} \mathrm{H}\right)_{2}$ ], or it also can react directly with alcohol $(\mathrm{ROH})$ to delivered a monoester, such as $\left(\mathrm{CH}_{2} \mathrm{CO}\right)_{2} \mathrm{O}+\mathrm{ROH} \rightarrow$ $\mathrm{RO}_{2} \mathrm{CCH}_{2} \mathrm{CH}_{2} \mathrm{CO}_{2} \mathrm{H}$. Furthermore, the catalysts are employed to favor yield of this esterification including DMAP and DCC in this synthesis procedure of BPS. After conducting the above-mentioned reaction, the chemical structure of BPS is investigated from the ${ }^{1} \mathrm{H}-\mathrm{NMR}$ spectra (Figure 3a), the peak at $2.47 \mathrm{ppm}$ belongs to acetylenic protons $(\underline{\mathbf{H}} \mathrm{C} \equiv \mathrm{C}-)$ of BPS. The new peaks at $4.21 \mathrm{ppm}$ and $4.07 \mathrm{ppm}$ are characteristic resonance of two protons adjacent to oxygen ( $\left.-\underline{\mathrm{CH}}_{2}-\mathrm{O}-\right)$ and ( $\left.-\mathrm{C} \underline{\mathbf{H}}_{2}-\mathrm{CO}-\right)$ of BPS, respectively [17]. ${ }^{13} \mathrm{C}-\mathrm{NMR}$ spectra of BPS is shown in Figure $3 \mathrm{~b}$, the peaks at $171.51 \mathrm{ppm}$ and $28.85 \mathrm{ppm}$ are with an order to carbons of $-\mathrm{OO} \underline{\mathbf{C}}-\mathrm{CH}_{2}-$ and $-\mathrm{OOC}-\underline{\mathbf{C}} \mathrm{H}_{2} \underline{\mathbf{C}} \mathrm{H}_{2}-\mathrm{COO}-$; in particular, the peaks at $52.48 \mathrm{ppm}, 75.33 \mathrm{ppm}$ and $76.97 \mathrm{ppm}$ belong to the carbon adjacent to carboxyl oxygen $(\mathrm{HC} \equiv \mathrm{C}-$ $\left.\underline{\mathbf{C}} \mathrm{H}_{2}-\mathrm{O}-\right)$, and carbons of alkyne $[(\mathrm{H} \underline{\mathbf{C}} \equiv \mathrm{C}-)$ and $(\mathrm{HC} \equiv \underline{\mathbf{C}}-$ $\left.\overline{\mathrm{C}} \mathrm{H}_{2}-\right)$ ], respectively [17]. These results suggest that BPS is synthesized successfully via the esterification reaction. 
a)

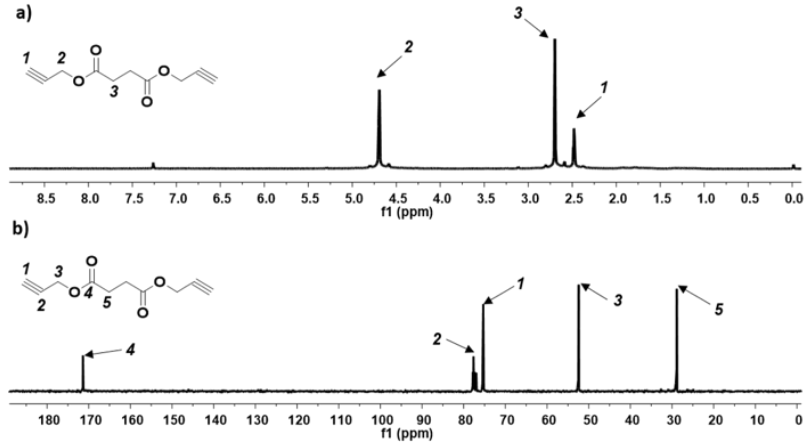

Fig. 3 (a) ${ }^{1} \mathrm{H}-\mathrm{NMR}$, (b) ${ }^{13} \mathrm{C}-\mathrm{NMR}$ spectra of $\mathrm{BPS}$ in $\mathrm{CDCl}_{3}$.

Additionally, FTIR spectroscopy is used (Figure 4a) to more determined chemical property of BPS, which is concerned to results in the presence of alkyne groups and carboxyl groups on BPS. From FTIR spectras, the peaks at $3300 \mathrm{~cm}^{-1}, 2200 \mathrm{~cm}^{-1}$, and $1,750 \mathrm{~cm}^{-1}$ correspond to stretching vibration bands of alkyne groups $(\mathrm{HC} \equiv \mathrm{C}$, and $\mathrm{C} \equiv \mathrm{C})$, and carboxyl groups $(\mathrm{C}=\mathrm{O})$, respectively. As such, the acetylene groups are successfully combined on BPS molecules. Moreover, in addition to investigation of successful synthesis of BPS, the specific characterizations of BPS are further confirmed through DSC and TGA analysis as well. Specifically, the glass transition temperature $\left(T_{g}\right)$, crystallization temperature $\left(T_{c}\right)$ and melting temperature $\left(T_{m}\right)$ of the synthesized BPS is determined more by DSC (Figure 4b) $\left(\mathrm{t}=-120^{\circ} \mathrm{C}-50{ }^{\circ} \mathrm{C}\right)$. Besides, TGA is a simple and accurate method for studying the decomposition pattern and the thermal stability of material [18]. The decomposition temperature $\left(\mathrm{T}_{\mathrm{d}, \max }\right)$ is the temperature showing the maximum rate of decomposition in TGA curve, corresponding to the lowest point in DTG curve. In Figure $4 c, T_{d}$, max of the synthesized BPS is $214.03{ }^{\circ} \mathrm{C}$, it means that the $\mathrm{T}_{\mathrm{d} \text {, max }}$ is rapidly decomposed to reach its initial decomposition temperature with an extreme low char residue (about $1.5 \%$ at $\left.400{ }^{\circ} \mathrm{C}\right)$. Overall, BPS with terminal alkyne group is used as a healing agent to be successful prepared in this esterification.
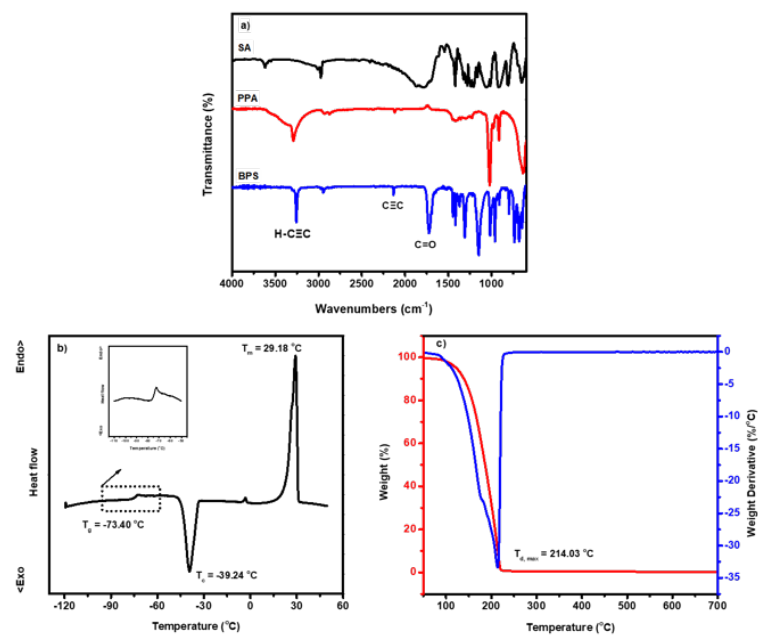

Fig. 4 (a) FT-IR spectra, (b) DSC curve and (c) TGA - DTG curves of BPS.

\subsection{Preliminary healing property of bis-propargyl-} succinate injected crosslinked polyurethane

As known, chemical structure of GAP contains azide and hydroxyl (diol) groups. In addition to form the crosslinked PU by the reaction of available hydroxyl (diol, $-\mathrm{OH})$ groups on GAP chain and isocyanate $(-\mathrm{N}=\mathrm{C}=\mathrm{O})$ compound (IPDI)
(Figure 1b), the available azide groups on the chain of the crosslinked PU can react with alkyne compound (BPS) to heal the crosslinked PU (Figure 1c) with the different assuming cuts (i.e.: seven specimens of crosslinked PUs with the different assuming cuts are designed as shown in Figure 2). This is seen as a new method to survey and develop more healing ability in the first studies of this material.

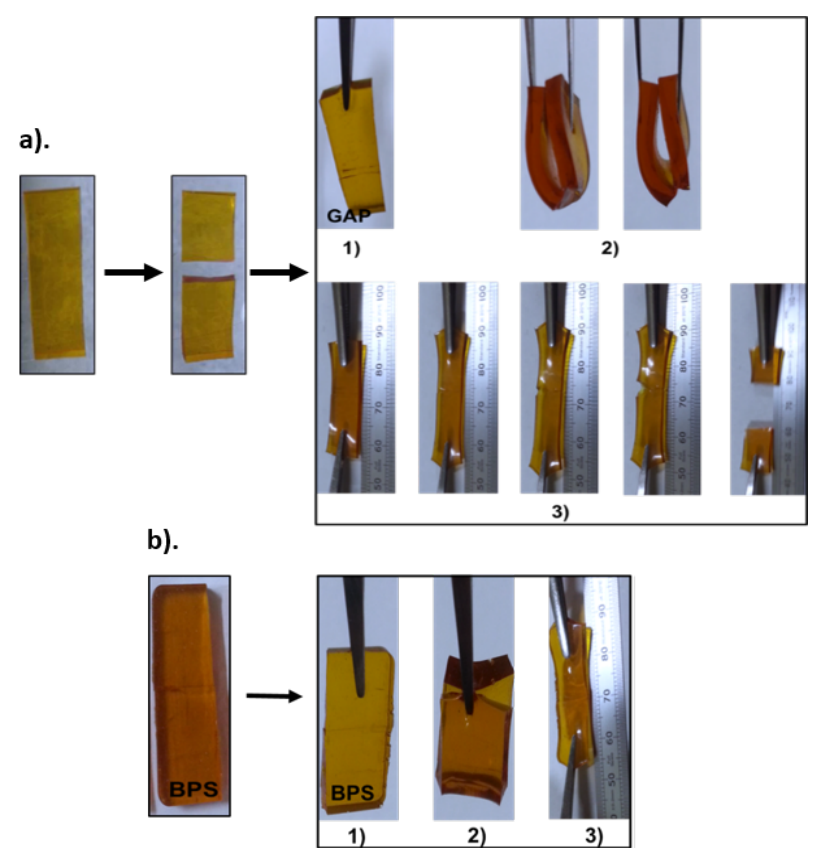

Fig. 5 (a) Crosslinked PU without BPS still (1) merged together but it separates out when (2) bending force and (3) stretching force are employed. (b) BPS injected crosslinked PU still (1) merged together when (2) bending force and (3) stretching force are given to the preliminary healable "azide-alkyne" click.

To investigate the effect of "azide-alkyne" click on the damaged regions of the crosslinked PU, it is conducted by cutting into two pieces (Figure 5a), and the synthesized BPS is employed as a healing agent to be applied on the cut regions of the crosslinked PU (Figure 5b). These cut regions of all samples are then connected together and stored in an oven at $60{ }^{\circ} \mathrm{C}$. After 7 days, the preliminary healing ability of the crosslinked PU is monitored by visual observation (Figure 5). The results indicate that the phenomena of the cut regions of the crosslinked PUs without BPS (Figure 5a) is concerned as a control experiment. The samples have been merged together owing to intermolecular hydrogen bondings of the crosslinked PU; however, the connected surfaces of the cut regions of the crosslinked PU are easily separated upon the bending and stretching forces. This demonstrates that the intermolecular hydrogen bondings of the crosslinked PU is not only weak but also unhealable in these cut regions of the crosslinked PU. In contrast, the phenomena of the samples with BPS (Figure 5b) shows that of the connected regions are not separated upon the bending and stretching forces after merging each other. The results suggest that there is not only intermolecular hydrogen bondings but also the presence of the preliminary healable "azide-alkyne" click (i.e.: the reaction of the cut regions of the crosslinked PU and BPS); however, the "azide-alkyne" click is major reaction to heal these damaged samples. Furthermore, their preliminary healing mechanism can also base on the diffusion of BPS into the cut regions of the crosslinked PU to conduct healing ability [19]. The preliminary healing material is described schematically as shown in Figure 6. Hence, BPS is seen as a healing agent 
instead of nature of a glue in this case. It really benefits for development of the capsule-based self-healing materials from GAP material source in the future works.

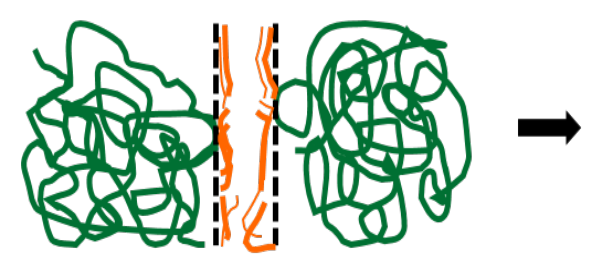

Injecting BPS on the cut surface of GAP-based PU

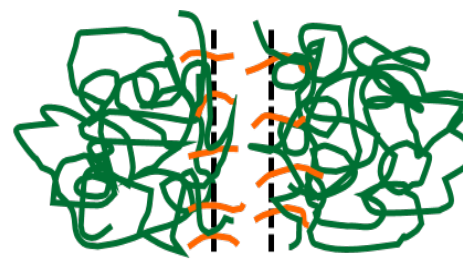

Diffusion

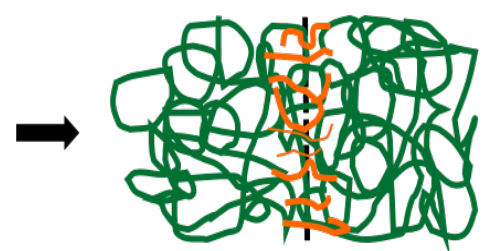

Connecting together

Fig. 6 Preliminary healing mechanism.

\subsection{Mechanical property of bis-propargyl-succinate injected crosslinked polyurethane}

In addition to the results of the visual observation, the preliminary healing efficiency of these samples is determined to evaluate the preliminary healing ability as well. In Figure $7 \mathrm{a}$, the specimens are designed with the different assuming cuts as shown in Figure 2. Then, the synthesized BPS is employed to directly inject into the cut positions of the abovedesigned specimens $\left(\mathrm{t}=60{ }^{\circ} \mathrm{C}\right)$. After 7 days, these specimens $[(1)-(7)]$ are all taken out from the oven (Figure $7 b$ ), which are then applied for tensile strength test to investigate the stress and strain at break and calculate the preliminary healing efficiency $(\eta)[20]$ :

$\eta=\frac{\sigma_{\text {healed }}-\sigma_{\text {ref }}}{\sigma_{\text {origin }}-\sigma_{\text {ref }}} \cdot 100 \%$

where $\sigma_{\text {healed }}$ and $\sigma_{\text {ref }}$ are the stress at break of specimen with and without BPS in each cutting case, respectively. $\sigma_{\text {origin }}$ is the stress at break of original specimen without cutting, which is named specimen $(0)$.

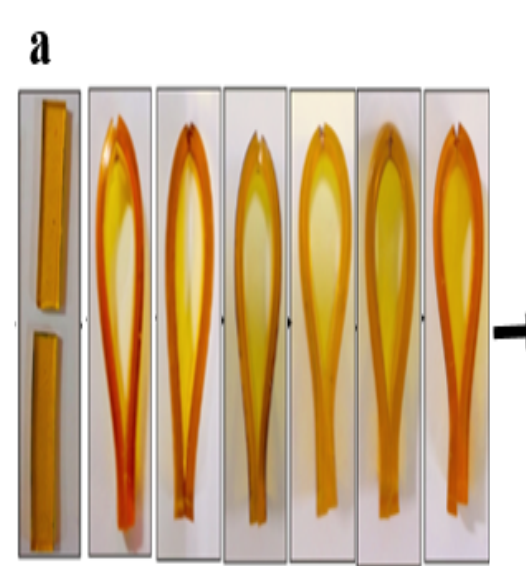

(1) (2) (3) (4) (5) (6) (7) b

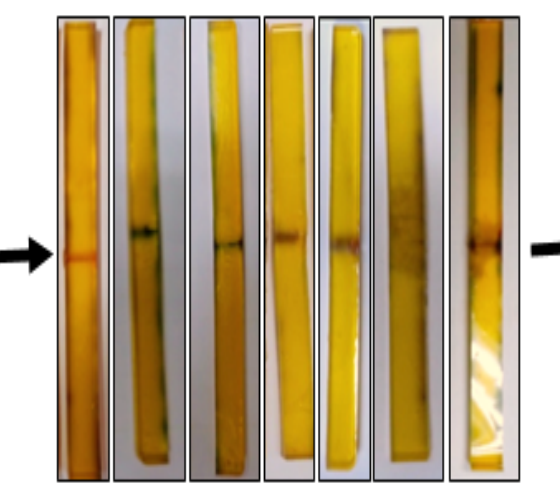

(1) (2) (3) (4) (5) (6) (7) c

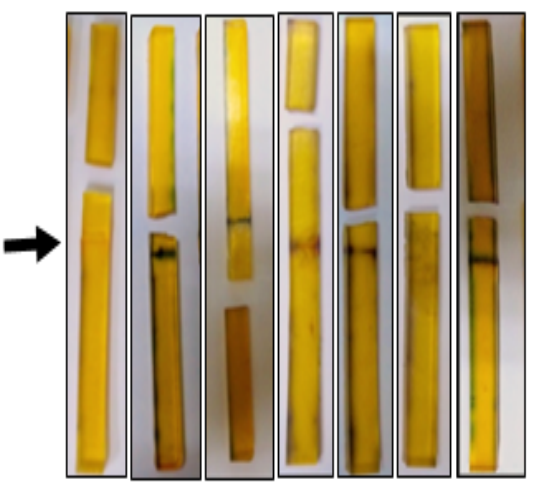

(1) (2) (3) (4) (5) (6) (7)

Fig. 7 (a) The cut crosslinked PUs of specimens [(1) - (7)], (b) BPS injected the cut crosslinked PUs after 7 days, (c) The specimens [(1) - (7)] after tensile strength test.

In Figure $7 b$, the various cut regions of the crosslinked PUs are all already healed. It indicates that there is the appearance of "azide-alkyne" click between the synthesized BPA and the healed samples (various cut regions of the crosslinked PUs); in particular, the fractured positions of all specimens are only occurred at the positions of the crosslinked PU after the tensile strength test (Figure 7c). Hence, the healed positions of the specimens become stronger basing on the preliminary healable "azide-alkyne" click. As listed in Table 2, the calculated values of the preliminary healing efficiencies are higher than $32.0 \%$ for all specimens, resulting that the synthesized BPS is considered as a healing agent instead of nature of a glue in this phenomena. Specifically, the stress at break of the healed samples is all higher than that of samples without BPS (reference samples) [i.e.: $0.169-0.218 \mathrm{MPa}$ (the healed samples) $>0-0.151 \mathrm{MPa}$ (the reference samples)]. The preliminary healing efficiency of all specimens is in a range of $32.1-86.0 \%$, and the highest preliminary healing efficiency of the healed sample (1) is achieved to be $86.0 \%$ mainly due to be non-impacted of the reference specimen (i.e.: the stress at break of the reference sample (1) is 0). Moreover, the stress at break of all specimens is lower to be compared to $0.244 \mathrm{MPa}$ of the original crosslinked PU. Additionally, the elongation at break of the healed samples is in the range of $140-172 \%$ comparing to $233 \%$ of the original crosslinked PU, and their modulus is the range of $0.169-0.313 \mathrm{MPa}$ comparing to $0.201 \mathrm{MPa}$ of the original crosslinked PU. These results indicate that the all healed samples assign to a brittle failure owing to the rigid crosslinked triazole networks ("azide-alkyne" click) [21], instead of the presence of voids in crosslinked PU that arises from the reaction of isocyanate with moisture releasing carbon dioxide (Figure 1b). 
Table 2. Mechanical properties of BPS injected the cut crosslinked PUs.

\begin{tabular}{c|c|c|c|c|c}
\hline \multirow{2}{*}{ Specimen } & \multicolumn{5}{|c}{ Mechanical properties } \\
\cline { 2 - 6 } & $\begin{array}{c}\text { Stress at break } \\
\text { (MPa) }\end{array}$ & $\begin{array}{c}\text { Elongation at } \\
\text { break } \\
\text { (\%) }\end{array}$ & $\begin{array}{c}\text { Modulus } \\
\text { (MPa) }\end{array}$ & $\begin{array}{c}\text { Stress at break of } \\
\text { reference } \\
\text { (MPa) }\end{array}$ & $\begin{array}{c}\text { Preliminary } \\
\text { healing efficiency } \\
\text { (\%) }\end{array}$ \\
\hline (0) & $0.244 \pm 0.031$ & $233 \pm 48$ & $0.201 \pm 0.040$ & -- & -- \\
$(\mathbf{1})$ & $0.210 \pm 0.050$ & $172 \pm 70$ & $0.267 \pm 0.017$ & 0 & $86.0 \pm 1.3$ \\
$(\mathbf{2})$ & $0.174 \pm 0.019$ & $159 \pm 49$ & $0.227 \pm 0.013$ & $0.137 \pm 0.018$ & $34.3 \pm 2.1$ \\
$(\mathbf{3})$ & $0.206 \pm 0.039$ & $140 \pm 43$ & $0.313 \pm 0.047$ & $0.150 \pm 0.015$ & $59.7 \pm 1.9$ \\
$\mathbf{( 4 )}$ & $0.169 \pm 0.018$ & $152 \pm 26$ & $0.171 \pm 0.013$ & $0.134 \pm 0.019$ & $32.1 \pm 2.0$ \\
$\mathbf{( 5 )}$ & $0.218 \pm 0.015$ & $164 \pm 27$ & $0.206 \pm 0.027$ & $0.177 \pm 0.020$ & $60.5 \pm 2.1$ \\
$\mathbf{( 6 )}$ & $0.195 \pm 0.014$ & $150 \pm 23$ & $0.217 \pm 0.024$ & $0.161 \pm 0.016$ & $40.5 \pm 2.2$ \\
(7) & $0.186 \pm 0.015$ & $158 \pm 14$ & $0.169 \pm 0.025$ & $0.151 \pm 0.015$ & $37.7 \pm 2.0$ \\
\hline
\end{tabular}

As shown in Figure 8, two factors in each specimen include the interface length (L) and the healed area (A) impacting to the stress at break $(\sigma)$ of the healed specimens and their preliminary healing efficiency (HE). First, in comparison between specimens (1) and (3), the interface lengths of both specimens are same. In contrast, their healed areas are different, resulting that the healed area of the specimen (1) is higher than that of specimen (3). It indicates that the stress at break and preliminary healing efficiency of specimen (1) are higher than those of specimen (3), as well as the healed area impacts to the stress at break and preliminary healing efficiency. Second, in other comparisons between specimens (4) and (7), and that of specimens (7) and (5), it is opposite with above relationship of the specimens (1) and (3). Resulting that the stress at break and preliminary healing efficiency of specimen (4) are higher than those of specimen (7), which is similar for that of specimens (7) and (5), it means that the interface length impacts to the stress at break and preliminary healing efficiency. Next, in other comparisons between specimens (1) and (2), and that of specimens (5) and (6), the interface lengths and healed areas of both specimens (1) and (5) are higher than those of both specimens (2) and (6), respectively. The results suggest that the stress at break and preliminary healing efficiency of both specimens (1) and (5) are higher than those of specimens (2) and (6), respectively, which leads to one of the interface length and the healed area is probably impact to the stress at break and preliminary healing efficiency. Hence, in other comparisons between specimens (2) and (3), and that of specimens (4) and (6), the interface lengths of both specimens (2) and (4) are lower than those of both specimens (3) and (6), respectively, which is opposite for their healed areas. It indicates that the stress at break and preliminary healing efficiency of both specimens (2) and (4) are lower than those of specimens (3) and (6), respectively, which leads to the interface length impacts more than that of the healed area to the stress at break and preliminary healing efficiency. Detailed studies on the effects of the parameter factors are still underway in our study.

In general, the various cut regions of all specimens (the crosslinked PU) are healed by the synthesized BPS, as well as the healed positions of the specimens become stronger mainly owing to the preliminary healable "azide-alkyne" click. Thus, BPS is employed as a healing agent in this case, which becomes a promising candidate for self-healing material in GAP-based PU matrix. Moreover, this study opens an approach for fabrication of capsule-based self-healing materials in the future works.

\begin{tabular}{|c|c|}
\hline 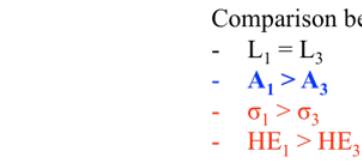 & 1) and \\
\hline $\begin{array}{ll}\text { Comparison between (4) and (7): } \\
-\quad \mathrm{A}_{4}=\mathrm{A}_{7} \\
-\quad \mathbf{L}_{4}<\mathbf{L}_{7} \\
-\quad \sigma_{4}<\sigma_{7} \\
-\quad \mathrm{HE}_{4}<\mathrm{HE}_{7}\end{array}$ & $\begin{array}{l}\text { Comparison between (7) and (5): } \\
-\quad \mathrm{A}_{7}=\mathrm{A}_{5} \\
-\mathbf{L}_{7}<\mathbf{L}_{5} \\
-\quad \sigma_{7}<\sigma_{5} \\
-\quad \mathrm{HE}_{7}<\mathrm{HE}_{5}\end{array}$ \\
\hline $\begin{array}{l}\text { Comparison between (1) and (2): } \\
-\quad \mathrm{A}_{1}>\mathrm{A}_{2} \\
-\quad \mathrm{L}_{1}>\mathrm{L}_{2} \\
-\quad \sigma_{1}>\sigma_{2} \\
-\quad \mathrm{HE}_{1}>\mathrm{HE}_{2}\end{array}$ & $\begin{array}{l}\text { Comparison between (5) and (6): } \\
-\quad \mathrm{A}_{5}>\mathrm{A}_{6} \\
-\mathrm{L}_{5}>\mathrm{L}_{6} \\
-\quad \sigma_{5}>\sigma_{6} \\
-\quad \mathrm{HE}_{5}>\mathrm{HE}_{6}\end{array}$ \\
\hline $\begin{array}{l}\text { Comparison between (2) and (3): } \\
-\quad \mathbf{L}_{2}<\mathbf{L}_{3} \\
-\quad \mathrm{A}_{2}>\mathrm{A}_{3} \\
-\quad \sigma_{2}<\sigma_{3} \\
-\quad \mathrm{HE}_{2}<\mathrm{HE}_{3}\end{array}$ & $\begin{array}{l}\text { Comparison between (4) and (6): } \\
-\quad \mathbf{L}_{4}<\mathbf{L}_{6} \\
-\quad \mathrm{A}_{4}>\mathrm{A}_{6} \\
-\quad \sigma_{4}<\sigma_{6} \\
-\quad \mathrm{HE}_{4}<\mathrm{HE}_{6}\end{array}$ \\
\hline
\end{tabular}

Fig. 8 Comparisons between specimens in BPS injected crosslinked PU with the different assuming cuts.

\section{Conclusion}

In summary, BPS is successfully synthesized by one-stage method from cheap reactants, which is employed to investigate the preliminary healing efficiency in the various cut regions of the crosslinked polyurethanes (GAP-based PU) via the formation of 1,2,3-triazole groups. The stress at break of the healed samples $[(1)-(7)]$ is higher than that of the reference samples $[(1)-(7)]$, but it is lower than that of the original crosslinked PU (0) [i.e: $0-0.151 \mathrm{MPa}$ (the reference samples) $<0.169-0.218 \mathrm{MPa}$ (the healed samples) $<0.244$ MPa (the original crosslinked PU)]. Besides, the calculated values of the preliminary healing efficiencies are higher than $32.0 \%$ for all specimens; in particular, the highest preliminary healing efficiency of the healed sample (1) is achieved to be $86.0 \%$. Moreover, the results of the visual observation show the preliminary healing mechanism can be based on the diffusion of BPS into the cut regions of the crosslinked PU to conduct healing ability, this is also agreed with the healed positions of the specimens become stronger owing to the preliminary healable "azide-alkyne" click. Hence, BPS is seen as a healing agent instead of nature of a glue in this phenomena, as well as it becomes a promising candidate for self-healing material in GAP-based PU matrix. The results suggest that this study opens an approach for fabrication of capsule-based self-healing materials from GAP material in the future works.

Abbreviations

GAP Glycidyl azide polymer 


$\begin{array}{ll}\text { BPS } & \text { Bis-propargyl-succinate } \\ \text { PU(s) } & \text { Polyurethane(s) } \\ \text { DMAP } & \text { 4-(Dimethylamino)pyridine } \\ \text { DCC } & \text { N-N'-dicyclohexylcarnodiimide } \\ \text { SA } & \text { Succinic anhydride } \\ \text { PPA } & \text { Propargyl alcohol } \\ \text { MC } & \text { Dichloromethane } \\ \text { NMR } & \text { Nuclear magnetic resonance spectroscopy } \\ \text { FT-IR } & \text { Fourier-transform infrared spectroscopy } \\ \text { TGA } & \text { Thermogravimetric analysis } \\ \text { DTG } & \text { Derivative thermogravimetry } \\ \text { DSC } & \text { Differential scanning calorimeter }\end{array}$

$\begin{array}{ll}\text { L } & \text { Interface length } \\ \text { A } & \text { Healed area }\end{array}$

HE Preliminary healing efficiency

Acknowledgments

The authors thank the support of Can Tho University.

This is an Open Access article distributed under the terms of the Creative Commons Attribution License

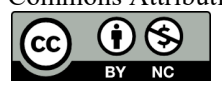

\section{References}

1. Yuan, L., Liang, G. Z., Xie, J. Q., Li, L., Guo, J., "Preparation and characterization of poly(urea-formaldehyde) microcapsules filled with epoxy resins", Polymer, 47, 2006, pp.5338-5349.

2. Suryanarayana, C., Rao, K. C., Kumar, D., "Preparation and characterization of microcapsules containing linseed oil and its use in self-healing coatings", Progress in Organic Coatings, 63, 2008, pp.72-78.

3. Cosco, S., Ambrogi, V., Musto, P., Carfagna, C., "Properties of poly(urea-formaldheyde) microcapsules containing an epoxy resin", Journal of Applied Polymer Science, 105, 2007, pp.1400-1411.

4. Keller, M. W., Sottos, N. R., "Mechanical properties of microcapsules used in a self-healing polymer", Experimental Mechanics, 46, 2006, pp.725-733.

5. Ahangari, M. G., Fereidoon, A., Jahanshahi, M., Sharifi, N., "Effect of nanoparticles on the micromechanical and surface properties of poly(urea-formaldehyde) composite microcapsules", Composites Part B-Engineering, 56, 2014, pp.450-455.

6. Rostovtsev, V. V., Green, L. G., Fokin, V. V., Sharpless, K. B., "A stepwise Huisgen cycloaddition process: Copper(I)-catalyzed regioselective "ligation" of azides and terminal alkynes", Angewandte Chemie-International Edition, 41, 2002, pp.2596-+.

7. Tornoe, C. W., Christensen, C., Meldal, M., "Peptidotriazoles on solid phase: [1,2,3]-triazoles by regiospecific copper(I)-catalyzed 1,3dipolar cycloadditions of terminal alkynes to azides", Journal of Organic Chemistry, 67, 2002, pp.3057-3064.

8. Gorman, I. E., Willer, R. L., Kemp, L. K., Storey, R. F., "Development of a triazole-cure resin system for composites: evaluation of alkyne curatives", Polymer, 53, 2012, pp.2548-2558.

9. Schnurch, M., Flasik, R., Khan, A. F., Spina, M., Mihovilovic, M. D., Stanetty, P., "Cross-coupling reactions on azoles with two and more heteroatoms", European Journal of Organic Chemistry, 2006, 2006, pp.3283-3307.

10. Grosu, I., Mager, S., Ple, G., Martinez, R., "Considerations about the chirality of the saturated six-membered rings with two or more heteroatoms", Chirality, 8, 1996, pp.311-315.

11. Binder, W. H., Sachsenhofer, R., "'Click' chemistry in polymer and material science: an update", Macromolecular Rapid Communications, 29, 2008, pp.952-981.
12. Binder, W. H., Sachsenhofer, R., "'Click' chemistry in polymer and materials science", Macromolecular Rapid Communications, 28, 2007, pp.15-54.

13. Diaz, D. D., Punna, S., Holzer, P., Mcpherson, A. K., Sharpless, K. B., Fokin, V. V., Finn, M. G., "Click chemistry in materials synthesis. 1. Adhesive polymers from copper-catalyzed azidealkyne cycloaddition", Journal of Polymer Science Part a-Polymer Chemistry, 42, 2004, pp.4392-4403.

14. Li, Z. M., Seo, T. S., Ju, J. Y., "1,3-dipolar cycloaddition of azides with electron-deficient alkynes under mild condition in water", Tetrahedron Letters, 45, 2004, pp.3143-3146.

15. Krol, P., "Synthesis methods, chemical structures and phase structures of linear polyurethanes. Properties and applications of linear polyurethanes in polyurethane elastomers, copolymers and ionomers", Progress in Materials Science, 52, 2007, pp.915-1015.

16. Hein, C. D., Liu, X. M., Wang, D., "Click chemistry, a powerful tool for pharmaceutical sciences", Pharmaceutical Research, 25, 2008, pp.2216-2230.

17. Keicher, T., Kuglstatter, W., Eisele, S., Wetzel, T., Krause, H., "Isocyanate-free curing of glycidyl azide polymer (GAP) with bispropargyl-succinate (II)", Propellants Explosives Pyrotechnics, 34, 2009, pp.210-217.

18. Zohuriaan, M. J., Shokrolahi, F., "Thermal studies on natural and modified gums", Polymer Testing, 23, 2004, pp.575-579.

19. Sun, D. W., An, J. L., Wu, G., Yang, J. L., "Double-layered reactive microcapsules with excellent thermal and non-polar solvent resistance for self-healing coatings", Journal of Materials Chemistry A, 3, 2015, pp.4435-4444.

20. Dong, B. Q., Han, N. X., Zhang, M., Wang, X. F., Cui, H. Z., Xing, F., "A microcapsule technology based self-healing system for concrete structures", Journal of Earthquake and Tsunami, 7, 2013.

21. Reshmi, S. K., Vijayalakshmi, K. P., Thomas, D., Arunan, E., Nair, C. P. R., "Glycidyl azide polymer crosslinked through triazoles by click chemistry: curing, mechanical and thermal properties", Propellants Explosives Pyrotechnics, 38, 2013, pp.525-532. 